\title{
Investigation of Atopy in Primary Cutaneous CD30+ T-Cell Lymphoproliferative Disorders
}

\author{
Vonderheid EC ${ }^{*}$, Hamilton $\mathrm{RG}^{2}$ and Kadin $\mathrm{ME}^{3}$ \\ ${ }^{1}$ Sydney Kimmel Cancer Center, Johns Hopkins Medical Institutions, USA \\ ${ }^{2}$ Asthma and Allergy Center, Johns Hopkins University School of Medicine, USA \\ ${ }^{3}$ Department of Pathology and Laboratory Medicine, Rhode Island Hospital and \\ Department of Dermatology, Boston University and Roger Williams Medical Center, USA
}

\section{Research Article \\ Volume 2 Issue 1}

Received Date: December 31, 2016

Published Date: January 18, 2017

DOI: $10.23880 /$ cdoaj 16000108

*Corresponding author: Eric Vonderheid, 37580 S. Desert Sun Drive, Tucson, AZ 85739, USA, Tel: +520-825-2699; Email: evonder1@jhmi.edu

\section{Abstract}

Background: A link between atopy and primary cutaneous CD30+ lymphoproliferative disorders (CD30CLPD), which encompasses lymphomatoid papulosis (LyP) and primary cutaneous anaplastic large cell lymphoma (pcALCL), has been suggested in the literature.

Objective: Investigate whether patients with CD30CLPD have an atopic diathesis.

Methods: We reviewed our experience with 157 patients with LyP and 23 patients with pcALCL for: (1) the patients' personal history of seasonal allergic rhinitis, allergic asthma or atopic dermatitis/eczema, (2) a history of these conditions in a first degree family member, and (3) a serum total IgE level that exceeds $100 \mathrm{IU} / \mathrm{mL}$ which in adults has been used to signify "probable atopy". Also recorded were a history of patients' allergic reactions to medications and absolute peripheral blood eosinophil counts.

Results: A personal history of at least one atopic disorder was noted for $38 \%$ and $17 \%$ of patients with LyP and pcALCL, respectively. Allergic rhinitis was the most frequent allergy in both LyP and pcALCL subsets (27\% overall) with asthma and eczema reported in $10 \%$ or fewer cases. The prevalence of allergic rhinitis in these subsets was significantly lower than the $38.2 \%$ prevalence observed for healthy controls derived from the Interlymph project. However, recall bias and unstructured collection of data may contribute to these different results. The frequency of allergic drug reactions, most often to penicillin type drugs, were similar for both LyP and pcALCL subsets ( $28 \%$ overall). The frequency of penicillin reactions for patients with pcALCL was significantly higher than the $11.46 \%$ rate reported by Albin ( $\mathrm{P}=0.01)$. At least one atopic condition was recorded for a parent, sibling or child in about $20 \%$ of patients with either LyP or pcALCL. Multiple atopic conditions in first degree family members occurred in about a third of these cases, in particular for family members of patients with LyP-C. Mean total serum IgE values were significantly increased in patients with LyP and pcALCL compared to published reference values for non-atopic adults in the US and Europe. Between 30 to $36 \%$ of patients with LyP type A, LyP type C and pcALCL, but not LyP type B, had total IgE values that exceeded $100 \mathrm{IU} / \mathrm{ml}$. 
Although not statistically significant, mean IgE levels tended to increase from LyP-B to LyP-A to LyP-C and pcALCL, suggesting a possible role of atypical CD30+ cells in directly stimulating IgE production. Eosinophilia was present in $4 \%$ of cases.

Conclusion: This study provides evidence that serum total IgE is often increased in patients with CD30CLPD. The IgE> $100 \mathrm{IU} / \mathrm{ml}$ threshold for probable atopy was exceeded in about a third of patients with LyP-A, LyP-C and pcALCL, but not LyP-B. However, a link with atopy was not supported by review of the patients' personal and family history that was obtained at the time of the initial examination rather than using a formal questionnaire. Additional studies with measurement of allergen specific IgE antibodies with attention to bacterial superantigens might be more informative.

Keywords: Atopy; Lymphomatoid papulosis; Anaplastic large cell lymphoma; IgE

Abbreviations: CTC: Cutaneous T Cell Lymphoma; ECTCL: Erythrodermic CTCL; MF: Mycosis Fungoides; IgE-t: Serum Total IgE; CD30CLPD: Primary Cutaneous CD30+ T-cell lymphoproliferative Disorders; LyP: Lymphomatoid Papulosis; pcALCL: Primary Cutaneous CD30+ anaplastic large cell lymphoma; GM: Geometric Mean.

\section{Introduction}

Atopy has been defined as a personal or familial tendency to produce IgE antibodies in response to allergen exposure, usually to aerosolized, injected or ingested proteins, and to develop typical symptoms such as asthma, rhino conjunctivitis, or eczema/dermatitis [1]. For most epidemiological studies, atopy requires a demonstration of an increased allergen-specific serum $\operatorname{IgE}$ response ( $>0.35 \mathrm{kUA} / \mathrm{L}$ ) or positive prick skin test to any common food or inhalant allergen. An increased level of total serum IgE (IgE-t) has also been associated with atopic conditions (especially asthma) with an IgE-t value $>100 \mathrm{IU} / \mathrm{mL}$ used to define "probable atopy" [2,3]. However, some atopic individuals have IgE-t values less than $100 \mathrm{IU} / \mathrm{mL}$ and IgE-t may be increased in individuals with various non-atopic conditions (Supplementary Table 1).

In this study, we report our experience with atopy in patients with primary cutaneous CD30+ T-cell lymphoproliferative disorders (CD30CLPD) which encompass lymphomatoid papulosis (LyP) at one end of the clinical spectrum and primary cutaneous anaplastic large cell lymphoma (pcALCL) at the other end [4,5]. The possibility of a biologic relationship between CD30CLPD and atopy has been suggested by several studies. Nijsten [6] noted an atopic condition in 18 of 35 (51\%) cases of childhood LyP (allergic rhinitis in 12 patients, allergic asthma in 3 patients, atopic dermatitis in 2 patients and allergic rhinitis plus asthma in 1 patient). Fletcher [7] reported 3 cases of pcALCL and one case of LyP associated with active atopic dermatitis, and Ishida [8] added one additional case of pcALCL with atopic dermatitis. In the study by the International Lymphoma Epidemiology Consortium (InterLymph), Wang [9] found a significantly higher personal history of hay fever in patients with pcALCL (46\%) than controls (21\%).

\section{Materials and Methods}

Data were obtained from a Cutaneous Lymphoma Registry approved by the Institutional Review Board at Johns Hopkins University. CD30CLPD cases were classified into 5 subtypes of LyP (types A to E) and pcALCL based on recommended clinical-pathological correlations $[4,10]$. Because histo-immunopathologic findings vary among lesions and over time, all available skin biopsy specimens were reviewed for each patient. In two prior series of LyP [11,12], cases that had more than one LyP subtype were placed in a "mixed LyP" category. Because multiple specimens were reviewed, 35 patients in this series with LyP fell into this category, i.e., LyP-A + LyP-B (13 patients), LyP-A + LyP-C (21 patients), and LyPC + LyP-B (1 patient). In addition, 5 patients with pcALCL had evidence of LyP-A on at least one other specimen including 2 patients with both LyP-A and LyP-C. It is worth noting that LyP-C was the most frequent LyP subtype within the "mixed LyP" category in our series (22/35 patients) and that reported by of El Shabrawi (6/7 patients) [11]. Additionally, patients with "mixed LyP" may have an increased risk of developing another lymphoma [12]. For this reason, patients that might otherwise be classified as "mixed LyP" in our study were diagnosed using the most "advanced lesion" encountered 
for each patient. Accordingly, LyP-A + LyP-B cases were included in the LyP-A category, LyP-A + LyP-C cases were included in the LyP-C category, etc. The review also identified one case each of the recently described LyP-D and LyP-E subtypes and these were classified separately.

The patient population consisted of 157 patients with LyP (63 non-Hispanic White males, 77 non-Hispanic White females, 4 Black males, 10 Black females, and 3 Asian males; median age, 52 years, range 2 to 92 years) and 23 patients with pcALCL (14 non-Hispanic White males, 5 non-Hispanic White females, 2 Black males, 1 Black female, and 1 Hispanic male; median age, 56 years, range 19 to 75 years). The LyP cohort was comprised mostly of LyP type A (109 patients) followed by LyP-C (37 patients), LyP-B (9 patients) and single instances of LyP-D and LyP-E. The relative proportions of LyP-A, B and C $(69.4 \%, 5.7 \%$ and $23.6 \%)$ are similar to other series $[11,12]$.

An atopic diathesis was investigated in 3 ways using information obtained at the time of the initial evaluation:

(1) The patients' personal history of seasonal allergic rhinitis (hay fever), asthma or atopic dermatitis/eczema.

(2) A history of these conditions in a first degree family member (parents, siblings, or children).

(3) A serum IgE-t level that exceeds $100 \mathrm{IU} / \mathrm{mL}$ (serologic evidence of atopy) [2,3].

Also recorded were a history of the patients' allergic reactions to medications and their absolute peripheral blood eosinophil counts. Skin tests for allergy were not performed.

In the absence of suitable control populations at our center, we compared our findings with normal adult controls reported in various publications. For the lifetime prevalence of atopic disorders, controls were selected from the InterLymph Project [13]. Because lifetime prevalence of atopic diseases differs significantly between European and North American centers, the odds ratios were calculated for controls evaluated at 5 centers in the United States (Figure 1) [14]. Specifically the calculated rates for allergic rhinitis/hay fever, asthma and eczema were $38.2 \%(1139 / 2982), 10.32 \% \quad(443 / 4291)$, and $7.21 \%$ (156/2163), respectively. For the prevalence of allergic reactions to penicillin or derivatives, we used the $11.46 \%$ (1348/11,761) frequency from Albin's survey [15]. IgE-t levels were compared against several published series of non-atopic controls [2,16-23].

Between 1980 and 2002, IgE-t was quantified in various commercial reference laboratories. IgE- $t$ values were expressed as international units $/ \mathrm{ml}(\mathrm{IU} / \mathrm{mL})$ which is the same as kilounits/liter (kU/L). For samples after 2002, IgE-t was measured in the Johns Hopkins Dermatology Allergy and Clinical Immunology Reference Laboratory using an FDA approved immunological method (Immuno CAP, Thermofisher Scientific, Uppsala, Sweden). The assay was calibrated using the World Health Organization Human IgE reference preparation [24]. Values expressed as nanograms/ml were converted to $\mathrm{IU} / \mathrm{mL}$ by dividing by 2.4 [25].

The reference value for healthy non-allergic adults provided by these laboratories was a geometric mean of $14 \mathrm{IU} / \mathrm{mL}$ (mean $\log _{10} \mathrm{IgE}-\mathrm{t}, 1.146 \mathrm{IU} / \mathrm{mL}$ ) with 122 $\mathrm{IU} / \mathrm{mL}$ given as the geometric mean plus 2 standard deviations (SD). Thus, assuming the population studied was representative, values of IgE-t up to $122 \mathrm{IU} / \mathrm{mL}$ should encompass $97.5 \%$ of the healthy non-allergic (nonatopic) adult population. These reports also indicate that type 1 hypersensitivity (atopic genesis) is "highly probable" if serum IgE-t values exceed $100 \mathrm{IU} / \mathrm{mL}$ whereas values less than $20 \mathrm{IU} / \mathrm{mL}$ indicate that an atopic predisposition was unlikely. These guidelines were derived from a 1981 Swedish study of 175 non-atopic adult patients for which the IgE geometric mean was 13.2 $\mathrm{IU} / \mathrm{mL}$ (mean $\log _{10} \mathrm{IgE}-\mathrm{t}, 1.121 \mathrm{IU} / \mathrm{mL}$ ) and geometric mean plus 2SD of $114 \mathrm{IU} / \mathrm{mL}$ [2]. Of note, in a more recent study, the geometric mean for IgE-t at a center in Portland, Oregon was similar to that of Sweden [26]. Therefore, for this study, we used total serum IgE-t $>100$ $\mathrm{IU} / \mathrm{mL}$ threshold to indicate an atopic predisposition in adults and $>122 \mathrm{IU} / \mathrm{mL}$ as an abnormally high value.

\section{Statistics}

Results of laboratory studies were given as mean values \pm 1 standard deviation (SD) and/or median value with a range. Because IgE-t values and absolute eosinophil counts from population samples are skewed right, the distribution of these variables were normalized by log transformation and the geometric mean, i.e., the anti-log of the mean $\log _{10}$ IgE-t value [27]. This allows for comparisons of mean values using parametric statistical tests (analysis of variance and t-tests). Welch's unequal variances t-test was used to compare CD30CLPD results with large control populations. Results were confirmed using non-parametric tests (Mann-Whitney and KruskalWallis tests) on non-transformed data in some instances. For cases without eosinophils reported on manual white cell differential counts, the absolute eosinophil count was set at 3.5 cells $/ \mu \mathrm{L}$ to allow calculation of log values. Fisher's and Pearson's chi-square exact tests were used to test categorical data in 2 by 2 and $\mathrm{R}$ by $\mathrm{C}$ tables, 
respectively. Pearson's correlation coefficient was used to determine the correlation between log IgE-t and log absolute eosinophil counts. The statistical software used in the study were SYSTAT10 and SPSS 13.0 for Windows, SPSS, Inc. (Chicago, IL) and StatXact-3, Cytel, Inc. (Cambridge, MA).

\section{Results}

\section{Personal and family history of allergy and diagnostic group}

Table 1 summarizes the information about personal and family history of allergy obtained at the time of the initial evaluation for patients with CD30CLPD. At least one atopic disorder (allergic rhinitis/hay fever, asthma or eczema) was noted for $38 \%$ and $17 \%$ of patients with LyP and pcALCL, respectively. Indeed one of our patients with LyP-C had long standing active atopic dermatitis when evaluated. The difference in the frequency between LyP and pcALCL was not statistically significant $(\mathrm{P}=0.063)$. There also was no difference among the 3 major subtypes of LyP $(\mathrm{P}=0.296)$. Allergic rhinitis was the most frequent allergy in both LyP and pcALCL subsets (27\% overall) with asthma and eczema reported in $10 \%$ or fewer cases. More than one atopic condition occurred in $13(8.3 \%)$ of LyP patients and none of the pcALCL patients $(\mathrm{P}=0.379)$.

\begin{tabular}{|c|c|c|c|c|c|c|}
\hline \multicolumn{7}{|c|}{ Number with condition/Number in cohort (\%) } \\
\hline Diagnosis & $\begin{array}{c}\text { Atopic } \\
\text { History* }\end{array}$ & $\begin{array}{l}\text { Allergic } \\
\text { Rhinitis }\end{array}$ & Asthma & Eczema & $\begin{array}{l}\text { Penicillin } \\
\text { Allergy }\end{array}$ & $\begin{array}{l}1^{0} \text { Relatives } \\
\text { with Atopy } \dagger\end{array}$ \\
\hline $\begin{array}{c}\text { All } \\
\text { CD30CLPD } \neq\end{array}$ & $64 / 180(35.6)$ & $49 / 180(27.2)$ & $13 / 180(7.2)$ & $17 / 180(9.4)$ & $31 / 180(17.2)$ & $37 / 174(21.3)$ \\
\hline LyP & $60 / 157(38.2)$ & $46 / 157(29.3)$ & $13 / 157(8.3)$ & $16 / 157(10.2)$ & $24 / 157(15.3)$ & $34 / 154(22.1)$ \\
\hline Type B & $5 / 9(56)$ & $5 / 9(56)$ & $1 / 9(11)$ & $1 / 9(11)$ & $2 / 9(22)$ & $4 / 9(44)$ \\
\hline Type A & $38 / 109(34.9)$ & $30 / 109(27.5)$ & $10 / 109(9.2)$ & $7 / 109(6.4)$ & $17 / 109(15.6)$ & $17 / 107(15.9)$ \\
\hline Type C & $17 / 37(46)$ & $11 / 37(30)$ & $2 / 37(5)$ & $8 / 37(22)$ & $5 / 37(14)$ & $12 / 36(33)$ \\
\hline pcALCL & $4 / 23(17)$ & $3 / 23(13)$ & $0 / 23(0)$ & $1 / 23(4)$ & $7 / 23(30)$ & $4 / 23$ (17) \\
\hline
\end{tabular}

Table 1: Frequency of allergic conditions in patients with primary cutaneous CD30+ lymphoproliferative disorders and first degree relatives.

Abbreviations: CD30CLPD: primary cutaneous CD30+ lymphoproliferative disorders; LyP: lymphomatoid papulosis; pcALCL: Primary cutaneous anaplastic large cell lymphoma

*Atopy limited to allergic rhinitis/hay fever, asthma or atopic dermatitis/eczema.

†Parents, siblings or children.

¥Includes one case each of LyP-D and LyP-E.

When compared to data derived from the Inter-lymph project, the lifetime prevalence of allergic rhinitis in both the LyP and pcALCL subsets was statistically lower than the 38.2\% prevalence observed in controls (LyP vs. control, $\mathrm{P}=0.028$; pcALCL vs. control, $\mathrm{P}=0.016$ ). The frequency of allergic drug reactions were similar for both LyP and pcALCL subsets ( $28 \%$ overall) with reactions to penicillin type drugs reported most often in both cohorts. When compared to the $11.46 \%$ frequency of penicillin reactions reported by Albin, [15] only the pcALCL cohort had a significantly higher allergy rate $(\mathrm{P}=0.012)$.
With regard to atopy in first degree family members (parents, siblings, children), similar frequencies (about $20 \%$ ) were reported for both LyP and pcALCL cohorts (P= 0.788 ). More than one atopic condition in family members was reported in about a third (12/37) of these cases. Overall patients with CD30CLPD who had a personal history of an atopic disorder were twice as likely to have a family member with atopy as patients without atopy (21/63 or $33 \%$ vs. $17 / 114$ or $14.9 \%, P=0.007)$. This was true for LyP-C patients $(\mathrm{P}=0.014)$ but not for LyP-A, LyP$\mathrm{B}$ nor pcALCL. However, the strong family history of atopy recorded for patients with LyP-C (12/36 or 33\%) was not 


\section{Clinical Dermatology Open Access Journal}

statistically higher than the $27 \%$ frequency for 147 adult controls reported by Hajdarbegovic $(\mathrm{P}=0.537)$ [28].

\section{Serum total IgE}

IgE-t levels were measured on 117 with LyP and 14 patients with pcALCL (Table 2). One patient with LyP-C co-existing with active atopic dermatitis had an exceedingly high IgE-t value $(11,146 \mathrm{IU} / \mathrm{mL})$ and was excluded from the analysis. Above normal IgE-t values, defined as $>122 \mathrm{IU} / \mathrm{mL}$ (geometric mean +2 standard deviations) on laboratory reports, occurred in 31/116 $(27 \%)$ of LyP and $5 / 14(36 \%)$ pcALCL patients $(27.7 \%$ overall).

\begin{tabular}{|c|c|c|c|c|c|c|}
\hline \multicolumn{7}{|c|}{ Serum total IgE (IU/mL) } \\
\hline Diagnosis & No. & Mean \pm SD [GM] & $<20$ & $20-100$ & $>100$ & $>122$ \\
\hline All CD30CLPD & 130 & $1.64 \pm 0.77[43.7]$ & $41(32 \%)$ & 50 & $39(30 \%)$ & $36(28 \%)$ \\
\hline LyP\#* & 116 & $1.62 \pm 0.78[41.7]$ & $37(32 \%)$ & 45 & $34(29 \%)$ & $31(27 \%)$ \\
\hline Type-B & 5 & $1.32 \pm 0.38[20.9]$ & $2(40 \%)$ & 3 & $0(0 \%)$ & $0(0 \%)$ \\
\hline Type-A & 84 & $1.62 \pm 0.82[41.7]$ & $27(32 \%)$ & 32 & $25(30 \%)$ & $24(29 \%)$ \\
\hline Type-C* & 26 & $1.71 \pm 0.73[51.3]$ & $7(27 \%)$ & 10 & $9(35 \%)$ & $7(27 \%)$ \\
\hline pcALCL & 14 & $1.76 \pm 0.66[57.5]$ & $4(29 \%)$ & 5 & $5(36 \%)$ & $5(36 \%)$ \\
\hline
\end{tabular}

Table 2: Serum total IgE in primary cutaneous CD30+ lymphoproliferative disorders and other selected conditions.

Abbreviations: CD30CLPD: Primary cutaneous CD30+ lymphoproliferative disorders; LyP: Lymphomatoid papulosis; pcALCL: Primary cutaneous anaplastic large cell lymphoma.

\#Includes one case of LyP-E with IgE $9 \mathrm{IU} / \mathrm{mL}$.

*Excludes one case of LyP-C with active atopic dermatitis.

\Includes one case of hypopigmented MF and LyP-E with IgE-t of $27 \mathrm{IU} / \mathrm{mL}$.

†GM, geometric mean = anti-log of mean log IgE-t value.

Comparison of mean $\log _{10}$ IgE-t values showed no statistically significant differences between LyP patients and pcALCL patients $(\mathrm{P}=0.48)$. Although mean IgE-t levels tended to increase from LyP-B to LyP-A to LyP-C (Table 2, Figure 1), there was no significant difference among the 3 main LyP subtypes $(\mathrm{P}=0.61)$. Therefore the values for all LyP and pcALCL patients were combined for subsequent comparisons.

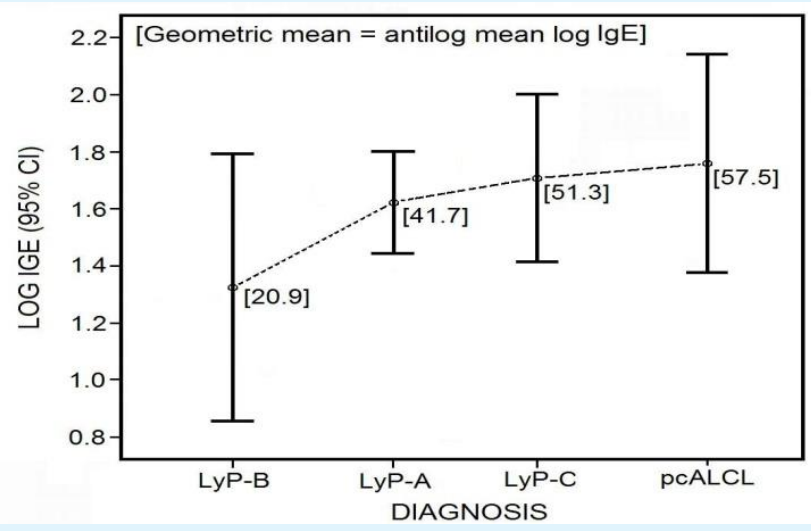

Figure 1: A possible trend toward increasing IgE values with more advanced histologic types of CD30CLPD was observed. However, the differences among the subtypes were not statistically significant $(\mathrm{P}=0.71)$.
Several publications have provided IgE-t values for non-atopic adults to establish normal reference ranges (Table 3) [2,16-22]. Because these studies likely concerned mostly White adult patients, we excluded nonWhite patients and patients under the age of 17 from our series for comparison with these published reference values.

IgE-t in our White adult patients with CD30CLPD (geometric mean $42.7 \mathrm{IU} / \mathrm{mL}$ ) was not only significantly higher than non-atopic adults from Zetterström's original study from Sweden (geometric mean 13.2), but also more recent studies from other European centers that tend to have higher IgE-t values than for Sweden [26]. Mean IgE-t values for CD30CLPD were also higher than non-atopic patients studied in Canada (geometric mean 12.1) [16].

More recently, IgE-t has been measured in two large population surveys in which non-atopic individuals were identified in the absence of allergen-specific $\operatorname{IgE}$ antibodies. For 4407 non-atopic adult subjects studied in the European Community Respiratory Health Survey [21], the IgE-t geometric mean was $23.8 \mathrm{IU} / \mathrm{mL}$ and for 3972 patients aged 6 years and older studied in the United States Health and Nutrition Examination 2005-2006 Survey, [23] the IgE-t geometric mean was $21.7 \mathrm{IU} / \mathrm{mL}$. 
These results are statistically lower $(\mathrm{P}<0.001)$ than the mean IgE values for our patients with CD30CLPD (Table $3)$.

In addition, given that IgE-t levels are higher in men than women, [19-21,23] we also compared our results with several centers that provided data on men and women (Table 3). For our 51 adult White men with CD30CLPD, the geometric mean was $66 \mathrm{IU} / \mathrm{mL}$ and this was significantly higher (all with $\mathrm{P}<0.001$ ) than geometric mean values reported for non-atopic men in the southwestern United States (geometric mean 20.3 $\mathrm{IU} / \mathrm{mL}$ ), Canada (geometric mean $12.6 \mathrm{IU} / \mathrm{mL}$ ), Greece (geometric mean $38.0 \mathrm{IU} / \mathrm{mL}$ ), northern Italy (geometric mean $28.8 \mathrm{IU} / \mathrm{mL}$ ), and Iran (geometric mean 19.1 $\mathrm{IU} / \mathrm{mL}$ ). Likewise the mean IgE-t values for the 53 adult White women with CD30CLPD in this series (geometric mean $28.2 \mathrm{IU} / \mathrm{mL}$ ) was significantly higher than female controls from these same regions with the exception of Greece (geometric mean $29.3 \mathrm{IU} / \mathrm{mL}, \mathrm{P}=0.899$ ) and Iran (geometric mean $23.9 \mathrm{IU} / \mathrm{mL}, \mathrm{P}=0.407$ ).

\begin{tabular}{|c|c|c|c|c|c|}
\hline Reference & Location & No. & Gender & Mean $\log _{10}$ IgE \pm SD [GM]* & P-value§ \\
\hline Current study $\dagger$ & Eastern USA & 51 & M & $1.82 \pm 0.79[66.1]$ & \\
\hline Holford-Strevens & Canada & 130 & M & $1.100 \pm 0.477[12.6]$ & $<0.001$ \\
\hline Klink & Southwest USA & 643 & M & $1.307 \pm 0.688[20.3] \neq$ & $<0.001$ \\
\hline Grigoreas & Greece & 536 & $\mathrm{M}$ & $1.580 \pm 0.450[38.0]$ & 0.037 \\
\hline Simoni & Northern Italy & 226 & M & $1.46 \pm 0.52[28.8]$ & 0.003 \\
\hline Shoormasti & Iran & 219 & M & $1.27 \pm 0.62[19.1]$ & $<0.001$ \\
\hline Current study & Eastern USA & 53 & $\mathrm{~F}$ & $1.45 \pm 0.74[28.2]$ & \\
\hline Holford-Strevens & Canada & 242 & $\mathrm{~F}$ & $1.072 \pm 0.491[11.8]$ & $<0.001$ \\
\hline Klink & Southwest USA & 786 & $\mathrm{~F}$ & $1.090 \pm 0.658[12.3] \ddagger$ & $<0.001$ \\
\hline Grigoreas & Greece & 276 & $\mathrm{~F}$ & $1.467 \pm 0.479[29.3]$ & 0.923 \\
\hline Simoni & Northern Italy & 331 & $\mathrm{~F}$ & $1.27 \pm 0.58[18.6]$ & 0.072 \\
\hline Shoormasti & Iran & 147 & $\mathrm{~F}$ & $1.37 \pm 0.66[23.9]$ & 0.428 \\
\hline Current study & & 104 & $\mathrm{M}+\mathrm{F}$ & $1.63 \pm 0.79[42.7]$ & \\
\hline Commercial labs & Eastern USA & NS & $\mathrm{M}+\mathrm{F}$ & $1.146[14.0]$ & \\
\hline Zetterström & Sweden & 175 & $\mathrm{M}+\mathrm{F}$ & $1.121 \pm 0.468[13.2]$ & $<0.001$ \\
\hline Holford-Strevens & Canada & 372 & $\mathrm{M}+\mathrm{F}$ & $1.083 \pm 0.477[12.1]$ & $<0.001$ \\
\hline Peltonen & Finland & 134 & $\mathrm{M}+\mathrm{F}$ & $1.161 \pm 0.416[14.5]$ & $<0.001$ \\
\hline Simoni & Northern Italy & 588 & $\mathrm{M}+\mathrm{F}$ & $1.462 \pm 0.519[29.0]$ & 0.025 \\
\hline Shoormasti & Iran & 366 & $\mathrm{M}+\mathrm{F}$ & $1.32 \pm 0.643[20.8]$ & $<0.001$ \\
\hline Carosso & Europe & 4407 & $\mathrm{M}+\mathrm{F}$ & $1.377 \pm 0.544[23.8]$ & $<0.001$ \\
\hline Gergen $\rrbracket$ & USA & 3972 & $\mathrm{M}+\mathrm{F} \#$ & $1.337 \pm 0.538[21.7]^{* *}$ & $<0.001$ \\
\hline
\end{tabular}

Table 3: Serum total IgE laboratory reference ranges for non-atopic adults from various centers.

${ }^{*} \mathrm{GM}$, geometric mean $=$ anti-log of the mean $\log _{10}$ IgE-t value

† White patients with ages 17 years or more (94 lymphomatoid papulosis and 10 primary cutaneous anaplastic large cell 


\section{Clinical Dermatology Open Access Journal}

lymphoma).

‡ Average of reported age group means and standard deviations.

$\S$ Comparison with current study by Welch's unequal variance t-test.

\# Includes children aged 6 and older

Tl Non-atopy defined as absence of allergen-specific IgE in serum.

** IgE values provided courtesy of Agustin Calatroni, M.S.

\section{Total IgE and smoking history}

It has been suggested that IgE-t levels increase as a result of smoking and this might contribute for the higher IgE-t levels in men than women [3,21,29-31]. Accordingly, information about the smoking habits of White adult men and women with CD30CLPD and corresponding IgE-t levels is shown in (Table 4). Although IgE-t levels were slightly higher in prior and active male smokers compared to non-smokers, the differences were not significant $(\mathrm{P}=0.40)$. Moreover, for both genders, heavy smokers tended to have lower IgE-t levels than light smokers. The distribution of number of patients according to their smoking habit (never, prior and active) for LyP and pcALCL cohorts was also compared and was not significant $(P=0.675$, data not shown). We conclude smoking habit has a negligible effect on IgE-t in our patient population.

\begin{tabular}{|c|c|c|c|c|c|c|}
\hline \multicolumn{7}{|c|}{ Serum total IgE (IU/mL) } \\
\hline Cohort§ & Smoking History & No. & Mean \pm SD $[G M]$ & P-value & $\operatorname{IgE}>100$ & P-value \\
\hline \multirow{5}{*}{ White Male $(n=46)$} & Never & 16 & $1.64 \pm 0.68[43.7]$ & $0.400^{*}$ & $4(25 \%)$ & $0.330 \dagger$ \\
\hline & Prior & 14 & $1.80 \pm 0.97[63.1]$ & & $5(36 \%)$ & \\
\hline & Current & 16 & $2.04 \pm 0.77[109.6]$ & & $8(50 \%)$ & \\
\hline & Light & 4 & $2.35 \pm 0.61[223.9]$ & $0.362 \ddagger$ & $3(75 \%)$ & $0.569 \#$ \\
\hline & Heavy & 12 & $1.93 \pm 0.81[85.1]$ & & $5(42 \%)$ & \\
\hline \multirow{5}{*}{ White Female $(n=47)$} & Never & 25 & $1.37 \pm 0.62[23.4]$ & $0.990^{*}$ & $4(16 \%)$ & $0.376 \dagger$ \\
\hline & Prior & 5 & $1.33 \pm 0.80[21.4]$ & & $1(20 \%)$ & \\
\hline & Current & 17 & $1.39 \pm 0.93[24.5]$ & & $6(35 \%)$ & \\
\hline & Light & 5 & $2.05 \pm 0.43[112.2]$ & $0.004 \ddagger$ & $3(60 \%)$ & $0.077 \#$ \\
\hline & Heavy & 10 & $0.82 \pm 0.72[6.6]$ & & $1(10 \%)$ & \\
\hline
\end{tabular}

Table 4: Correlation of smoking history and serum total IgE in adult White patients with primary cutaneous CD30+ lymphoproliferative disorders.**

** Smoking history was available on 136 patients with lymphomatoid papulosis and 17 patients with primary cutaneous anaplastic large cell lymphoma.

$\S$ No significant difference in the frequencies among non-smokers, ex-smokers, and active smokers $(\mathrm{P}=0.75)$. Therefore groups combined into CD30CLPD cohort.

* Analysis of variance: never vs. prior vs. current smoking

‡t-test: light vs heavy smoking

† Chi-square exact test

\# Fisher's exact test

\section{Total IgE $>100 \mathrm{IU} / \mathrm{mL}$ and atopic predisposition}

Another criterion used to identify atopic predisposition is a IgE-t value that exceeds $100 \mathrm{IU} / \mathrm{mL}$ $[2,3]$. For patients with CD30CLPD, an IgE- $t$ value $>100$
$\mathrm{IU} / \mathrm{mL}$ was more likely to be associated with personal

history of allergic rhinitis/hay fever, asthma or eczema than $\operatorname{IgE}$ values $\leq 100 \mathrm{IU} / \mathrm{mL}(\mathrm{P}=0.046$, Table 5). This 
occurred primarily because of patients with LyP-A (P= $0.024)$. However there was no association between IgE- $t>$ $100 \mathrm{IU} / \mathrm{mL}$ and atopy in first degree family relatives.

\begin{tabular}{|c|c|c|c|c|c|}
\hline \multicolumn{6}{|c|}{ History of Atopic Disorder* } \\
\hline Diagnosis & $\begin{array}{c}\text { IgE-t }>100 \\
\mathrm{IU} / \mathrm{mL}\end{array}$ & $\begin{array}{l}\text { Patients with } \\
\text { atopy/total }\end{array}$ & P-value & $\begin{array}{l}1^{0} \text { Relatives with } \\
\text { atopy/total } \neq\end{array}$ & P-value \\
\hline \multirow[t]{2}{*}{ All CD30CLPD $†$} & No & $26 / 91(29 \%)$ & 0.046 & $23 / 89(26 \%)$ & 0.826 \\
\hline & Yes & $19 / 40(48 \%)$ & & $9 / 40(23 \%)$ & \\
\hline \multirow[t]{2}{*}{ LyP† } & No & $26 / 82(32 \%)$ & 0.097 & $20 / 80(25 \%)$ & 1.0 \\
\hline & Yes & $17 / 35(49 \%)$ & & 9/35 (26\%) & \\
\hline \multirow[t]{2}{*}{ Type A } & No & $15 / 59(25 \%)$ & 0.024 & $10 / 57(18 \%)$ & 0.766 \\
\hline & Yes & $13 / 25(52 \%)$ & & $5 / 25(20 \%)$ & \\
\hline \multirow[t]{2}{*}{ Type C } & No & 9/17 (53\%) & 0.695 & $7 / 17(41 \%)$ & 1.0 \\
\hline & Yes & $4 / 10(40 \%)$ & & $4 / 10(40 \%)$ & \\
\hline \multirow[t]{2}{*}{ pcALCL } & No & $0 / 9(0 \%)$ & 0.11 & $3 / 9(33 \%)$ & 0.258 \\
\hline & Yes & $2 / 5(40 \%)$ & & $0 / 5(0 \%)$ & \\
\hline
\end{tabular}

Table 5: Relationship between serum total IgE as a serologic marker for atopy and personal and family history of an atopic disorder.

Abbreviations: CD30CLPD: Primary cutaneous CD30+ lymphoproliferative disorders; LyP, lymphomatoid papulosis; pcALCL: Primary cutaneous anaplastic large cell lymphoma.

* History of an atopic disorder (allergic rhinitis/hay fever, asthma or atopic dermatitis/eczema).

$\dagger$ includes patient with LyP-C and active atopic dermatitis.

キ Parents, siblings or children.

\section{Eosinophil counts}

Eosinophils are often increased in the peripheral blood of patients with an ongoing allergy. The reference range for absolute eosinophil count ranges between 5 and 500 cells/ $\mu \mathrm{L}$ [32]. Of patients with CD30CLPD, 7 of 174 (4\%) had absolute eosinophil counts that exceeded 500 cells/ $\mu \mathrm{L}$ (Table 6). There was no difference in mean absolute eosinophil counts between LyP and pcALCL (P= 0.40 ) nor among LyP-A, LyP-B and LyP-C subtypes ( $\mathrm{P}=$ $0.86)$.

\begin{tabular}{|c|c|c|c|c|c|}
\hline \multicolumn{7}{|c|}{ Absolute Eosinophil Counts/ $\boldsymbol{\mu L} \neq$} \\
\hline Diagnosis & No. & Median (range) & Log Absolute Count \pm SD [GM]\# & $\leq 500$ & $>500$ \\
\hline All CD30CLPD & 174 & $135.5(0-4788)$ & $1.92 \pm 0.76[83.2]$ & 167 & $7(4.0 \%)$ \\
\hline LyP* $\dagger$ & 152 & $138(0-4788)$ & $1.94 \pm 0.73[87.1]$ & 146 & $6(4.0 \%)$ \\
\hline Type A & 108 & $141(0-4788)$ & $1.94 \pm 0.76[87.1]$ & 103 & $5(4.6 \%)$ \\
\hline Type B & 8 & $108(50-312)$ & $2.11 \pm 0.31[128.8]$ & 8 & $0(0 \%)$ \\
\hline Type C $\dagger$ & 34 & $138(0-792)$ & $1.91 \pm 0.76[81.3]$ & 33 & $1(3 \%)$ \\
\hline pcALCL & 22 & $96(0-1114)$ & $1.76 \pm 0.90[57.5]$ & 21 & $1(5 \%)$ \\
\hline
\end{tabular}

Table 6: Absolute eosinophil counts in primary cutaneous CD30+ lymphoproliferative disorders. 
Abbreviations: CD30CLPD: Primary cutaneous CD30+ lymphoproliferative disorders; LyP: Lymphomatoid papulosis; pcALCL: Primary cutaneous anaplastic large cell lymphoma.

‡ For cases with no eosinophils observed on manual differential white cell count, log absolute eosinophil count set at 3.5 cells $/ \mu \mathrm{L}$.

\#GM, geometric mean = anti-log of the mean $\log _{10}$ IgE-t value

* Includes one case of LyP-D and one case of LyP-E with no eosinophils on manual leukocyte differential count.

$\dagger$ Excludes one case of LyP-C with active atopic dermatitis

Although the 62 CD30CLPD patients with personal history of atopy had a slightly higher absolute eosinophil count (median $144 / \mu \mathrm{L}$, range $0-1114$ ]) than 112 patients without atopy (median $125 / \mu \mathrm{L}$, range $0-4788$ ), the difference was not statistically significantly $(\mathrm{P}=0.11)$. Furthermore, there was no correlation between eosinophil and IgE-t levels (Pearson's correlation, $r=$ 0.04).

\section{Discussion}

In contrast to prior publications [6-9], our patients' personal and family history did not support the hypothesis that atopy is associated with CD30CLPD. Indeed, the rate of allergic rhinitis in our patients with pcALCL $(13 \%)$ in this retrospective study was much lower than the $46 \%$ reported for pcALCL in the InterLymph study [9]. However, the observed frequencies in our study may be erroneously low for several reasons: (1) a patients' history of allergic rhinitis or asthma might not have been recorded as part of a routine dermatologic evaluation whereas such information would be captured on a formalized questionnaire, (2) dermatologists identify atopic dermatitis as a specific entity whereas cited epidemiologic studies might include other eczematous dermatoses under a broader category of atopic eczema, and (3) a significant proportion of adults ( $>40 \%$ ) with an atopic condition in childhood do not recall that they had the problem (recall bias) [33]. For these reasons, we place more reliance on measurements of IgE-t and eosinophil counts as indicators of atopy even though these tests are not specific. A study that measures allergen-specific serum IgE levels in CD30CLPD would be more informative [34].

For patients with CD30CLPD, mean IgE-t levels are significantly higher than for non-atopic adult controls and $30 \%$ of patients have values that exceed $100 \mathrm{IU} / \mathrm{mL}$, a criterion used in our study to define probable atopy $[2,3]$. Several hypotheses might be considered to explain the increased IgE-t in CD30CLPD patients. The first is that atopic individuals might be at increased risk to develop CD30CLPD. To investigate this further, it would be necessary to compare CD30CLPD rates in atopic and non- atopic populations.

An alternative hypothesis is that development of CD30CLPD in atopic individuals results in increased IgE-t production in response to antigens encountered specifically in the skin. By definition, atopic individuals are genetically programmed to have heightened IgE responses to antigenic stimulation. This leads to the question of whether the increase in IgE-t in the setting of CD30CLPD is a non-specific response to inflammation in the skin or whether a specific response to one or more activating antigens encountered in skin lesions is playing a role. A third possibility is that the atypical CD30+ cells of LyP and pcALCL are elaborating cytokines that enhance production of IgE-t. These possibilities are not mutually exclusive.

It has been suggested that increased IgE-t in atopic individuals is comprised of a least two independent components: a cognate IgE fraction associated with atopic sensitization (i.e., allergen-specific IgE antibodies) and a non-cognate IgE fraction unrelated to atopic disease [35]. In support of a non-cognate response in CD30CLPD is the observation that IgE-t may be increased in some patients with a variety of inflammatory skin disorders other than atopic dermatitis (listed in Supplementary Table 1). However, it is possible that heightened IgE-t responses in these situations are occurring in individuals genetically predisposed to atopy. This includes entities such as burns and hidradenitis suppurativa that do not have an apparent allergic, eczematous or autoimmune component as part of the inflammatory response [36-38]. Pascual hypothesized that elevated IL-10 in hidradenitis suppurativa promotes B cell differentiation to plasma cells that produce the IgE $[38,39]$.

Consideration must also be given to the possibility of a cognate IgE response to a specific antigen in CD30CLPD. Although the pathogenesis of LyP and pcALCL is unknown, we and other investigators have speculated that a virus or other persistent antigen source acts to stimulate susceptible memory $\mathrm{T}$ cells that ultimately develop genetic alterations that favor disease development and progression $[40,41]$. In this regard, it 
might be informative to study CD30CLPD for IgE antibodies against staphylococcal and streptococcal superantigens, given the role of staphylococcal superantigens in the pathogenesis of atopic dermatitis [42], and the similar eruptive nature of LyP and acute guttate psoriasis which has been shown to be mediated by streptococcal superantigens $[43,44]$.

A third possibility that was suggested by the possible increase in IgE-t with more advanced CD30CLPD (Table 2 and Figure 1) is that the atypical CD30+ cells are elaborating cytokines that promote IgE-t production. For example, Yagi showed that IL-4 and IL-10 mRNA is increased in lesions of LyP and pcALCL [45]. Moreover, preliminary data from the Kadin laboratory indicates that these cells have readily detectable IL-13 in their cytoplasm by immunohistochemistry and that Mac-2A/2B cell lines derived from a patient with CD30CLPD secrete IL-13. IL-13 is known to promote Ig class switch of B cells to IgE synthesis [46]. The local production of IL-13 would explain the local accumulation of eosinophils in many lesions of CD30CLPD, but usually not LyP-B which often lack CD30+ cells [47]. It remains to be determined if the amount of cytokines secreted by the total biomass of CD30+ atypical cells in the skin is sufficient to cause an increase in IgE-t as suggested in Figure 1. In addition, whether the cytokine profile of the atypical CD30+ cells in atopic and non-atopic individuals differs requires further study.

\section{Conclusion}

In conclusion, we provide evidence that serum IgE-t is often increased in patients with CD30CLPD, specifically $27 \%$ and $36 \%$ of patients with LyP and pcALCL, respectively. The IgE-t $>100 \mathrm{IU} / \mathrm{ml}$ threshold for probable atopy was exceeded in $30-36 \%$ of LyP-A, LyP-C and pcALCL, but not LyP-B. Eosinophilia was present in $4 \%$ of cases. However, a link with atopy was not supported by review of the patients' personal and family history that was obtained at the time of the initial examination rather than using a formal questionnaire. Additional studies with measurement of allergen-specific IgE antibodies with attention to bacterial super antigens might be informative.

\section{Acknowledgment}

The work of Marshall Kadin is supported by the Drs. Martin and Dorothy Spatz Foundation.

\section{References}

1. Johansson SG, Bieber T, Dahl R, Friedmann PS, Lanier $B Q$, et al. (2004) Revised nomenclature for allergy for global use: report of the Nomenclature Review Committee of the World Allergy Organization, October 2003. J Allergy Clin Immunol 113(5): 832836.

2. Zetterström 0, Johansson SGO (1981)IgE concentrations measured by PRIST in serum of healthy adults and in patients with respiratory allergy. Allergy 36(8): 537-547.

3. Wüthrich B, Schindler C, Medici TC, Zellweger JP, Leuenberger P (1996) IgE levels, atopy markers and hay fever in relation to age, sex and smoking status in a normal adult Swiss population. SAPALDIA (Swiss Study on Air Pollution and Lung Diseases in Adults) Team. Int Arch Allergy Immunol 111(4): 396-402.

4. Kempf W (2014) Cutaneous CD30-positive lymphoproliferative disorders. Surg Pathol Clin 7(2): 203-228.

5. Wieser I, Tetzlaff MT, Torres Cabala CA, Duvic M (2016) Primary cutaneous CD30(+) lymphoproliferative disorders. J Dtsch Dermatol Ges 14(8): 767-782.

6. Nijsten T, Curiel-Lewandrowski C, Kadin ME (2004) Lymphomatoid papulosis in children: a retrospective cohort study of 35 cases. Arch Dermatol 140(3): 306312.

7. Fletcher CL, Orchard GE, Hubbard V, Whittaker SJ, Edelson RL, et al. (2004) CD30(+) cutaneous lymphoma in association with atopic eczema. Arch Dermatol 140(4): 449-454.

8. Ishida M, Hodohara K, Yoshii M, Okuno H, Horinouchi A, et al. (2014) Primary cutaneous anaplastic large cell lymphoma occurring in an atopic dermatitis patient: a case report with review of the literature with emphasis on their association. Int J Clin Exp Pathol 7(4): 1735-1741.

9. Wang SS, Flowers CR, Kadin ME, Chang ET, Hughes AM, et al. (2014) Medical history, lifestyle, family history, and occupational risk factors for peripheral T-cell lymphomas: the InterLymph Non-Hodgkin Lymphoma Subtypes Project. J Natl Cancer Inst Monogr 2014(48): 66-75. 
10. Campo E, Swerdlow SH, Harris NL, Pileri S, Stein H, et al. (2011) The 2008 WHO classification of lymphoid neoplasms and beyond: evolving concepts and practical applications. Blood 117(19): 5019-5032.

11. El Shabrawi-Caelen L, Kerl H, Cerroni L (2004) Lymphomatoid papulosis: reappraisal of clinicopathologic presentation and classification into subtypes A, B, and C. Arch Dermatol 140(4): 441-447.

12. de Souza A, el-Azhary RA, Camilleri MJ, Wada DA, Appert DL, et al. (2012) In search of prognostic indicators for lymphomatoid papulosis: a retrospective study of 123 patients. J Am Acad Dermatol 66(6): 928-937.

13. Morton LM, Sampson JN, Cerhan JR, Turner JJ, Vajdic $\mathrm{CM}$, et al. (2014)Rationale and design of the International Lymphoma Epidemiology Consortium (InterLymph) Non-Hodgkin Lymphoma Subtypes Project. J Natl Cancer Inst Monogr (48): 1-14.

14. Vajdic CM, Falster MO, de Sanjose S, Martínez-Maza O, Becker N, et al. (2009) Atopic disease and risk of nonHodgkin lymphoma: an Inter Lymph pooled analysis. Cancer Res 69(16): 6482-6489.

15. Albin S, Agarwal S (2014) Prevalence and characteristics of reported penicillin allergy in an urban outpatient adult population. Allergy Asthma Proc 35(6): 489-494.

16. Holford-Strevens V, Warren P, Wong C, Manfreda J (1984) Serum total immunoglobulin E levels in Canadian adults. J Allergy Clin Immunol 73(4): 516522.

17. Peltonen L, Havu VK, Mattila L (1988) Serum IgE in non-atopic adults and in dermatitis patients. Allergy 43(2): 152-158.

18. Klink M, Cline MG,Halonen M, Burrows B (1990) Problems in defining normal limits for serum IgE. J Allergy Clin Immunol 85(2): 440-444.

19. Grigoreas C, Pappas D, Galatas ID, Kollias G, Papadimos S, et al. (1993) Serum total IgE levels in a representative sample of a Greek population. I. Correlation with age, sex, and skin reactivity to common aeroallergens. Allergy 48(3): 142-146.

20. Simoni M, Biavati P, Baldacci S, Carrozzi L, Pedreschi M, et al. (2001) The Po River Delta epidemiological survey: reference values of total serum IgE levels in a normal population sample of North Italy (8-78 yrs). Eur J Epidemiol 17(3): 231-239.

21. Carosso A, Bugiani M, Migliore E, Antò JM, DeMarco R (2007) Reference values of total serum IgE and their significance in the diagnosis of allergy in young European adults. Int Arch Allergy Immunol 142(3): 230-238.

22. Shoormasti SR, Pourpak Z, Eshraghian MR, HaghiAshtiani MT, Jamali M, et al. (2010) The study of total IgE reference range in healthy adults in Tehran, Iran. Iran J Public Health 39(3): 32-36.

23. Gergen PJ, ArbesSJ, Calatroni A, Mitchell HE, Zeldin DC (2009) Total IgE levels levels and asthma prevalence in the US population: results from the National Health and Nutrition Examination Survey 2005-2006. J Allergy Clin Immunol 124(3): 447-453.

24. Hamilton RG, OppenheimerJ (2015) Serological IgE analysis in the diagnostic algorithm for allergic disease. J Allergy Clin Immunol Pract 3(6): 833-840.

25. Nye L, Merrett TG, Landon J, White RJ (1975) A detailed investigation of circulating IgE levels in a normal population. Clin Allergy 5(1): 13-24.

26. Burney P, Malmberg E, Chinn S, Jarvis D, Luczynska C, et al. (1997) The distribution of total and specific serum IgE in the European Community Respiratory Health Survey. J Allergy Clin Immunol 99(3): 314-322.

27. OlivierJ, Johnson WD, Marshall GD (2008) The logarithmic transformation and the geometric mean in reporting experimental IgE results: what are they and when and why to use them? Ann Allergy Asthma Immunol 100(4): 333-337.

28. Hajdarbegovic E, Nijsten T, WestgeestA, Habraken F, Hollestein L, et al. (2013) Decreased prevalence of atopic features in patients with psoriatic arthritis, but not in psoriasis vulgaris. J Am Acad Dermatol 68(2): 270-277.

29. Sherrill DL, Halonen M, Burrows B (1994) Relationships between total serum IgE, atopy, and smoking: a twenty-year follow-up analysis. J Allergy Clin Immunol 94(6): 954-962.

30. Sapigni T, Biavati P, Simoni M, Viegi G, Baldacci S, et al. (1998) The Po River Delta Respiratory Epidemiological Survey: an analysis of factors related to level of total serum IgE. Eur Respir J 11(2): 278- 
283.

31. Oryszczyn MP, Annesi-Maesano I, Charpin D, Paty E, Maccario J, et al. (2000) Relationships of active and passive smoking to IgE-t in adults of the Epidemiological Study of the Genetics and Environment of Asthma, Bronchial Hyperresponsiveness, and Atopy (EGEA). Am J Respir Crit Care Med 161(4): 1241-1246.

32. Valent P, Klion AD, Horny HP, Roufosse F, Gotlib J, et al. (2012) Contemporary consensus proposal on criteria and classification of eosinophilic disorders and related syndromes. J Allergy Clin Immunol 130(3): 607-612.

33. Mortz CG, Andersen KE, Bindslev-Jensen C (2015) Recall bias in childhood atopic diseases among adults in the Odense Adolescence Cohort Study. Acta Derm Venereol 95(8): 968-972.

34. Szefler SJ, Wenzel S, Brown R, Erzurum SC, Fahy JV, et al. (2015) Asthma outcomes: biomarkers. J Allergy Clin Immunol 129(3): S9-23.

35. Jackola DR, Blumenthal MN, Rosenberg A (2004) Evidence for two independent distributions of serum immunoglobulin $\mathrm{E}$ in atopic families: cognate and non-cognate IgE. Hum Immunol 65(1): 20-30.

36. Gleich GJ, Dunnette SL, Volenec FJ, ManiMM (1979) Quantification of serum IgE in patients with burns. Clin Allergy 9(2): 133-139.

37. Polacek V, Jira M, Fara M, Strejcek J, Konigova R (1987) Immunoglobulin E (IgE) in patients with severe burns, Burns. Burns Incl Therm Inj 13(6): 458461.

38. Pascual JC, García-Martínez FJ, Martorell A, González I, Hispan P (2016) Increased total serum IgE levels in moderate-to-severe hidradeniti ssuppurativa. $\mathrm{Br} \mathrm{J}$ Dermatol 175(5): 1101-1102.

39. Kobayashi N, Nagumo H, Agematsu K (2002) IL-10 enhances B-cell IgE synthesis by promoting differentiation into plasma cells, a process that is inhibited by CD27/CD70 interaction. Clin Exp Immunol 129(3): 446-452.
40. Kempf W, Kadin ME, Dvorak AM, Lord CC, Burg G, et al. (2003) Endogenous retroviral elements, but not exogenous retroviruses, are detected in CD30positive lymphoproliferative disorders of the skin, Carcinogenesis 24(2): 301-306.

41. Vonderheid EC, Kadin ME, Gocke CD (2011) Lymphomatoid papulosis followed by pityriasis lichenoides: a common pathogenesis? Am J Dermatopathol 33(8): 835-840.

42. SchlievertPM, Strandberg KL, Lin YC, Peterson ML, Leung DY (2010) Secreted virulence factor comparison between methicillin-resistant and methicillin-sensitive Staphylococcus aureus, and its relevance to atopic dermatitis. J Allergy Clin Immunol 125(1): 39-49.

43. Leung DY, Travers JB, Giorno R, Norris DA, Skinner R, et al. (1995) Evidence for a streptococcal superantigen-deriven process in acute guttate psoriasis. J Clin Invest 96(5): 2106-2112.

44. Davison SC, Allen MH, Mallon E, Barker JN (2001) Contrasting patterns of streptococcal superantigeninduced T-cell proliferation in guttate vs. chronic plaque psoriasis. Br J Dermatol 145(2): 245-251.

45. Yagi H, Tokura $Y$, Furukawa $F$, Takigawa $M$ Th2 (1996) Cytokine mRNA expression in primary cutaneous CD30-positive lymphoproliferative disorders: successful treatment with recombinant interferon-gamma. J Invest Dermatol 107(6): 827832.

46. Punnonen J, Aversa G, Cocks BG, McKenzie AN, Menon S, et al. (1993) Interleukin 13 induces interleukin 4independent IgG4 and IgE synthesis and CD23 expression by human B cells. Proc Natl Acad Sci USA 90(8): 3730-3734.

47. Agnarsson BA, Kadin ME (1989) Host response in lymphomatoid papulosis. Hum Pathol 20(8): 747-752. 